\title{
Developing Logical Divisions of Ideas in University Students ${ }^{\text {ee }}$ Expository Essays
}

\author{
Anselmus Sudirman ${ }^{1}$, Luky Tiasari ${ }^{2}$ \\ ${ }^{1,2}$ Lecturer, The English Education Study Program of Universitas Sarjanawiyata Tamansiswa (UST) Yogyakarta, Indonesia
}

\begin{abstract}
The objectives of this study toward the considerable knowledge of writing are to find out (1) the logical divisions of ideas development in university students' expository essays, and (2) university students' problems related to the development of logical divisions of ideas in writing expository essays. In order to investigate logical divisions of ideas, the researchers used a qualitative research fundamentally involved an in-depth interpretation of data. Participants were three university students who contributed data to the research in terms of expository essays documents and interviews. In an attempt to analyze these instruments, three main steps were worth considering: (1) measuring the coverage of a topic sentence, supporting sentences, and a concluding sentence in each expository essay, and (2) exploring logical divisions of ideas in each paragraph with respect to how unity, coherence and cohesion were directly related to each other, and (3) interpreting the likelihood of participants' problems in writing the essays. As might have been expected, the research findings show that the first essay inaccurately presented unity, coherence and cohesion in its introductory paragraph. The first body paragraph demonstrated unity, coherence or cohesion. The second and third body paragraphs elaborated unity and coherence significantly, but they lacked cohesion. The second essay presented unity and coherence in its introductory paragraph, but it lost its cohesion. The second and the third body paragraphs did not qualify unity, coherence and cohesion. Unfortunately, its second body paragraph contained the coherence whereas its unity and cohesion were elusively problematic. The last essay performed both unity and coherence in its introductory paragraph, and body paragraphs, yet they missed cohesion without question. The participants' problems in proving the unity ranged from the difficulties in finding out the essay topic, integrating ideas to the inappropriate development of ideas. In terms of cohesion, they found it difficult to determine correct dictions due to poor mastery of vocabulary, neologism, connections between sentences and paragraphs, and use of correct transition signals. The cohesion was unclearly stated since there were no linkages of ideas between sentences and paragraphs considerably. The emergent problems prevailing in participants' expository essays indicated illogical divisions of ideas in explaining key terms. Besides, the topics development was not well-grounded because of difficulties in setting out the generic structure of the expository essay and its organization of ideas.
\end{abstract}

Keywords: logical divisions, expository essays, unity, coherence, cohesion

\section{Introduction}

It is crucial to note that logical divisions of ideas have primarily become an important concept closely linked to unity, coherence and cohesion of ideas expressed in an expository essay. As an integral part of writing principles in what might be called "critical understandings" (Harper, 2010) for most essay writers to have, logical divisions of ideas sustain the unity of ideas set to determine how sentences, and paragraphs are constructed logically. Of course, the unity-related concern has long carried with it coherence that begins to emerge indicated by sentences that stick together in a paragraph or an essay by using transition signals.

This mode of connection has also been associated with cohesion that links either sentences or paragraphs functionally. In a general sense, the value of cohesion can be judged in a way that it undoubtedly displays a critical thinking on correct grammar usage, and vocabulary richness (Tanskanen, 2006). In considering how this notion has been associated with a wide range of composition knowledge, critical understandings fall into learners ${ }^{\text {ee }}$ writing that must show some forms of cohesion and coherence in their presentation of ideas (Dastjer and Samian, 2011).

As an outlet for self-expression, writing an expository essay offers students ways to keep consistent in exploring ideas that encourages self-awareness on understanding how theories can be put into the best practices. To add this, the basis of scholarly tradition rests mainly on the processes of learning to write to transform the world as a necessary function of maximizing consistencies in appreciating human values, culture-rich innovations and the power of literary perceptions and appreciations. In the spirit of that tradition lies a writing viewpoint that "to write is to be human, to find the voice, the power, and the authority to communicate" (Bloom, 2007).

As it is implicated in Boom's principle, writing can be a deeply-ingrained tradition that remarkably provides a sense of humanity in criticizing social injustice, absence of power, ethical disparities, and public policies. While this framework of ideas may depend on the processes of teaching and learning that bridge the gap between theories and practices of writing, it is also evident that students ${ }^{\text {ee }}$ collective activities work well in the classroom context. More importantly, if this is a true profile of EFL students ${ }^{\text {ee }}$ writing competence, it is common to highlight that their expository essays have a number of drawbacks, that is, illogically organized ideas, incorrect sentences, lack of vocabulary, poor mastery of the topics, and irrelevant use of dictions. To a certain extent, mistakes always pertain to the construction of sentences in the introductory paragraph, supporting (body) paragraphs and concluding paragraph (Phillips, 2004). Another line of criticism especially comes from Wulff et al (2009) who confirm that students ${ }^{\text {ee }}$ paragraphs may have logical divisions of ideas, but they lack unity and coherence due to inability to unite and sequence ideas well.

To put it bluntly, these problems need to be presented in this research because writing an expository essay is distinctly 


\section{International Journal of Science and Research (IJSR) \\ ISSN (Online): 2319-7064 \\ Index Copernicus Value (2013): 6.14 | Impact Factor (2014): 5.611}

characterized by appropriate use of unity, coherence, and cohesion at the pragmatic level. Another point to take into account is that the expository essay examines to what extent central features of students develop a thought relationship involving "cognitive view of writing" (Hyland, 2003), so that unswerving attempts to organize ideas logically can be made. The intricate items on the essay structural constructions can be identified to address topics and supporting details adequately.

The researchers chose expository essays because, as usual, they mark the intense use of formal, academic language that emphasizes evidence, "author"s content, style and organization" (Bloom, 2007) along with relevant information to digest. It is even possible to argue that expository essays are predominantly used in the contexts of academic fields, not only in how suitable patterns of writing are applied for today"s university students ${ }^{\text {ee }}$ writing activities, but also in how logical divisions of ideas address two research questions. First, what aspects are used in developing logical divisions of ideas in university students ${ }^{\text {ce }}$ expository essays? Second, what are university studentse problems in developing logical divisions of ideas in writing expository essays?

In line with such questions that largely represent critical understandings, this research sheds new light on answering (1) logical divisions of ideas used in developing university students $^{\text {ee }}$ expository essays, and (2) problems they commonly faced in applying logical divisions of ideas during writing expository essays.

\section{Literature Review}

\section{Logical Divisions of Ideas}

In the field of essay writing, definitions of logical divisions of ideas can be found. Arnaudet \& Barrett (1984) note that a common means of relating ideas in an essay paragraph is by dividing them into a thought relationship. Until recently, the term logical divisions of ideas is generally understood to mean the relation of ideas that strongly articulates certain items referring to the similar category of ideas and the writer is responsible for arranging them to be logical sequentially.

This activity is called logical divisions of ideas (Hinkel, 2004) mainly focusing on how the relationship between an analytical process and a disciplined thought process can be systematically built. Within the framework of this definition, the term analytical process is generally understood as a process of generating ideas by way of analyzing general categories. In a broad sense, a disciplined thought process can be defined as a process in which a writer intends to be disciplined in classifying general categories. For this reason, logical divisions of ideas attempt to divide a general category into its total number of natural parts (Arnaudet \& Barrett, 1984). It may cover a thought relationship of (a) the causes or effects of something, (b) the similarities or differences between things, and (c) the steps in a process, examples, and so forth. Each general category needs to be developed further to find out its extended elaborations, explanations and logical development of ideas (Lindsay, 2011).
As mentioned by Arnaudet \& Barrett (1984), common structures of logical divisions of ideas rely heavily on the coordinating conjunction "and" in following a sentence that connects the general ideas to make them interrelated. To demonstrate this, a topic in question can be divided by grouping ideas that have similarities in common. By doing so, the development of logical divisions of ideas requires a step-by-step structure of writing an introductory paragraph, the supporting (body) paragraphs, and a concluding paragraph (Oshima \& Hogue, 1997; Phillips, 2004) of an expository essay.

\section{Unity, Coherence and Cohesion}

Sherman et al. (2010) point out that expository essays should have unity, coherence and cohesion. Unity is the characteristic of a paragraph when all the sentences in it discuss one topic only (Karim \& Rachmadie, 1996), meaning that it makes meaningful contributions to only one main idea under discussion. The main idea is stated in the topic sentence, and each supporting sentence develops that idea (Oshima \& Hoque (1999). In other words, unity is a means to which all sentences or paragraphs in an essay become one, undivided in a way it discusses a single topic conceptually.

Meanwhile, coherence is defined as an orderly relationship among the parts in a whole essay or other literary work. Writing is coherent when the interconnections among clauses, sentences, and paragraphs are clearly and logically related to the main subject under discussion (Bloom, 2007). There are two ways of supporting coherence namely using transition words to create bridges from one sentence to the next, and being consistent in using verb tenses and point of view. In that sense, coherence is a way of putting sentences in a paragraph or an essay to stick together by using transition signals (Karim \& Rachmadie, 1996). Transition signals are words and phrases that connect the idea in one sentence with the idea in another sentence (Oshima \& Hogue, 2007) and Wallwork (2011).

One way to look at writing is to see it as marks on a page or a screen, coherent arrangements of words, clauses, and sentences, structural according to a system of rules (Hyland, 2003). Cohesion is concerned with a practice of interpreting what pronouns refer to in the text, what the conjunction relationships between sentences are, and how different words are used to refer to the same idea using repetition, synonyms, near synonyms, superordinates and general words (Halliday \& Hassan, 1976: 278) in Nation (2009). This implies to indicate that an expository essay relies on logical organization of ideas for the essay unity, coherence (Davis \& McKay, 1996) and cohesion.

\section{Expository Essays}

Expository essays are usually designed to explain, analyze, interpret, speculate, evaluate, persuade, or reflect. They usually have a three-part structure consisting of an introductory paragraph, the supporting (body) paragraphs and a concluding paragraph (Olson, 2003, Phillips, 2004 \& Bloom, 2007). 


\section{International Journal of Science and Research (IJSR) \\ ISSN (Online): 2319-7064 \\ Index Copernicus Value (2013): 6.14 | Impact Factor (2014): 5.611}

First, introductory paragraph identifies the topic (that is stated clearly), and provides the author's view of the topic, and shows the organization of the essay. For this reason, a paragraph writer attempts to grab readers ${ }^{\text {ee }}$ attention by setting a so-called thesis (the writer's argument or opinion) in the topic sentence and elaborating specific details under discussion (Phillips, 2004).

Second, supporting (body) paragraphs use a transition that a paragraph is a supporting paragraph, use a topic sentence to introduce the main idea of the paragraph and use details to develop the main idea of the paragraph. A good supporting paragraph should do three things. First, it should have a transition to show that it is a supporting paragraph. Then it should have a topic sentence to introduce the main idea of the supporting paragraph. Finally, it should have details to develop the main idea of the paragraph (Phillips, 2004).

Finally, concluding paragraph is useful to restate the thesis in a different way that is partly true. This paragraph draws conclusions from the rest of the previous paragraphs along with their central ideas to follow. The concluding part reminds the reader of the essay ses main point by summarizing key points and pointing out the the overall idea and supporting ideas (Phillips, 2004), coming full circle, exploring the significance of something, asking a question, offering new insights, etc.

\section{Research Method}

The method used for this study is a qualitative research that is fundamentally interpretive involving an interpretation of data. This includes developing a description, analyzing data for categories and making an interpretation or drawing conclusions about its meaning personally and theoretically (Creswell, 2003). Therefore, this study aims to explore logical divisions of ideas consisting of unity, coherence and cohesion in university students ${ }^{\text {ee }}$ expository essays by providing in-depth analysis of data particularly pertinent documents.

\section{Participants}

Three university students at the English Education Study Program of Universitas Sarjanawiyata Tamansiswa (UST) Yogyakarta, Indonesia during the academic year of $2013 / 2014$ were involved in this research. They were sophomores at the time this research was conducted from March 1, 2014 through August 1, 2014. Each of them provided an expository essay particularly a classification essay and two analytical expositions and information through one on one, in-person interview (Creswell, 2003). Their in-class writing assignments and the interview with them became documents selected from which things could be learned fully.

\section{Data Collection Procedures}

First, fourteen data involved multiple forms of in-class writing documents concerning expository essays were collected. Second, three documents were finally selected by referring to certain features such us fulfilling the classification and analytical features of an essay, and they were produced in the classroom on the day of data collection deadline. A day after the writing class was over, the researchers conducted a semi-structured in-person interview with three students whose writing assignments were chosen to confirm their assignments. The interview was useful because participants could not observed directly (Creswell, 2003).

\section{Data Analysis Procedures}

The researchers analyzed data from two instruments namely expository essays and interviews. The analysis of expository essays involved three main steps: (1) the analysis of an introductory paragraph that covers the topic sentence, supporting sentences, and a concluding sentence in an each paragraph (introductory, supporting and concluding paragraphs) of the documents, (2) the analysis of the logical division of ideas in terms of unity, coherence and cohesion in each paragraph (introductory, supporting and concluding paragraphs) of the related documents. The interpreted documents were put in a coding system of logical divisions of ideas involving unity, coherence and cohesion concepts in writing expository paragraphs. The analysis of interview documents involved creating codes qualitatively (Creswell, 2003), then identifying indictors that represented each sentence occurred in the interview texts.

\section{Findings and Discussions}

\section{Developing Logical Divisions of Ideas in University Students' Expository Essays}

Regardless of addressing no title, essay 1 has four paragraphs called an introductory paragraph, and three supporting (body) paragraphs. The detailed elaboration of the essay can be shown below:

\section{Essay 1: Classification}

\section{Introductory Paragraph}

Many people in the world like pets, for example, dogs. There are many kinds of dogs based on their group. Actually, there are 6 groups of dogs. They are categorized as sporting dogs, hound dogs, working dogs, terrier dogs, nonsporting dogs and toy dogs.

\section{Body Paragraph 1}

The first group is sporting dogs. This group consists of two dogs named American Cocker Spaniel and Labrador Retriever. These dogs are categorized as a sporting group because they are smart and can do sports, so we can enjoy sports with them. The second group is hound dogs that consist of three dogs namely Basset, Greyhound, and Dachshund. They are good at tracking small animals such as rabbit, fox, and squirrel.

\section{Body Paragraph 2}

The third group is working dogs. This group consist of four dogs namely German Shepherd, Collie, Boxer, and Saint Bernard. This dogs are good in working. They can do some activities like guard dog, movie actor, and farm dog. The fourth group is terrier dogs. This group consist of two dogs namely Fox Terrier and Scottie. Both of them are good to locate and drag out foxes.

\section{Volume 4 Issue 11, November 2015}




\section{International Journal of Science and Research (IJSR) ISSN (Online): 2319-7064 \\ Index Copernicus Value (2013): 6.14 | Impact Factor (2014): 5.611}

\section{Body Paragraph 3}

The fifth group is non-sporting dogs that consist of three dogs named Dalmatian, Standard Poodle, and Miniature Poodle. They just pets and not good in sport. The last group is toy dog. This group consists of one dog named Chihuahua. Its body is like a toy and its size is small. Thates all about dogs based on their groups. (By participant A)

\section{The Logical Division of Ideas}

\section{Introductory Paragraph}

The logical division of ideas of each paragraph in Essay 1 should be examined thoroughly to find out sustainable integral parts namely unity, coherence and cohesion in correctly constructed sentences and a dual linkage between sentences and paragraphs. In this way, the correct vocabulary usage, or necessary transition signal or commas, grammatical and lexical cohesions are important to consider.

Many people in the world like pets, for example, dogs. There are many kinds of dogs based on their group. Actually, there are 6 groups of dogs. They are categorized as sporting dogs, hound dogs, working dogs, terrier dogs, nonsporting dogs and toy dogs.

In terms of a unity, the introductory paragraph of Essay 1 above does not sustain its integral parts because the topic sentence "Many people in the world like pets, for example, dogs" does not match with the supporting ideas expressed in the supporting sentences such as kinds of dogs based on their groups and specifications. The inclusion of a key phrase "many people" in the topic sentence is not followed by an elaboration in the topic sentence to highlight who likes what dogs, but the essay writer jumps directly to the discussion of kinds of dogs. Moreover, the absence of a concluding sentence makes the discussion of a single topic "kinds of dogs" unfocused, unclear and digressed.

In line with its coherence, each sentence does not stick together because there is only a single transition signal used namely and, indicating that the idea in one sentence cannot be connected with the idea in other sentences. In line with cohesion, the introductory paragraph lacks "the relations of meaning" (Tanskanen, 2006) resulting in the ignorance of vocabulary richness, in addition to the misuse of grammatical cohesion (conjunction, substitution, and ellipsis) and the lexical cohesion (repetition, synonym, collocation). In other words, the meaning (a semantic element) is not clearly expressed in this paragraph due to dual flaws in the form of inappropriate grammatical and lexical cohesions and vocabulary.

\section{Body Paragraph 1}

The first group is sporting dogs. This group consists of two dogs named American Cocker Spaniel and Labrador Retriever. This dogs are categorized as a sporting group because they are smart and can do sports, so we can enjoy sports with them. The second group is hound dogs that consist of three dogs namely Basset, Greyhound, and Dachshund. They are good at tracking small animals such as rabbit, fox, and squirrel.
The supporting (body) paragraph 1 above meets the criteria of unity because its integral parts (the topic sentence, and supporting sentences) sustains a single topic the first group of dogs. Regardless of the fact that this paragraph lacks a concluding sentence, the coherence of each sentence in it is indicated by the correct use of transition signals or connectors and, because, so, and that. In addition, its cohesion marked by the close relation of meanings delineates richness of vocabulary, semantic and lexical cohesions to link sentences effectively.

\section{Body Paragraph 2}

The third group is working dogs. This group consist of four dogs namely German Shepherd, Collie, Boxer, and Saint Bernard. This dogs are good in working. They can do some activities like guard dog, movie actor, and farm dog. The fourth group is terrier dogs. This group consist of two dogs namely Fox Terrier and Scottie. Both of them are good to locate and drag out foxes.

The supporting (body) paragraph 2 above does not meet the criteria of unity because it suffers from a flaw that the integral parts (the topic sentence and supporting sentences) do not sustain each other to discuss a single topic the third group of dogs. Even, the absence a concluding sentence worsens this state of sustainable unity. In dealing with coherence, sentences stick together but the use of a single transition signal and indicates that each sentence in the paragraph does not cohere consistently.

Even worse, its cohesion is unclear because certain incorrect sentences cannot convey the meaning clearly caused by the inappropriate use of subject-verb agreement in the supporting sentences, "This group consist of four dogs namely German Shepherd, Collie, Boxer, and Saint Bernard" and "This group consist of two dogs namely Fox Terrier and Scottie." The correct forms should be based on the agreement that a singular subject takes a singular verb, so the sentences should be constructed correctly, "This group consists of four dogs namely German Shepherd, Collie, Boxer, and Saint Bernard" and "This group consist $\underline{\text { s }}$ of two dogs namely Fox Terrier and Scottie."

The singular demonstrative pronoun "this" is wrongly attached to a plural noun "dogs $s^{\text {ee }}$ in the supporting sentence "This dogs are good in working." This results in a grammatical fallacy. The singular demonstrative pronoun "this" should be changed into a plural form of demonstrative pronoun "these". In addition, the collocation "good at (doing something)" is incorrectly used in the supporting sentences, "This dogs are good in working" and "Both of them are good to locate and drag out foxes". The correct sentences are "These dogs are good at working" and "Both of them are good at locating and dragging out foxes". Thus, the cohesion is not marked by the close relation of meanings in the contexts of presenting vocabulary richness, semantic and lexical cohesions.

\section{Body Paragraph 3}

The fifth group is non-sporting dogs that consist of three dogs named Dalmatian, Standard Poodle, and Miniature Poodle. They just pets and not good in sport. The last group is toy dog. This group consists of one dog named 


\section{International Journal of Science and Research (IJSR) \\ ISSN (Online): 2319-7064 \\ Index Copernicus Value (2013): 6.14 | Impact Factor (2014): 5.611}

Chihuahua. Its body is like a toy and its size is small. That's all about dogs based on their groups.

The supporting (body) paragraph 3 meets the criteria of unity because its integral parts (the topic sentence, and supporting sentences) sustains a single topic the fifth group of non-sporting dogs. Unfortunately, this paragraph lacks a concluding sentence. The simple sentence "They just pets and not good in sport" suffers from drawbacks. First, the plural linking verb "are" that does not agree with the plural subject "they". Second, the collocation "good at (something)" does not match with the noun "sport". Third, the singular noun "sport" does not agree with the plural subject "they" (in this case dogs) because it implies that dogs might be good at different sports. Therefore, the form of this sentence should be like this "They are just pets and not good at sports". The typical logical division of ideas in Essay 1 can be seen in the following table.

Table 4: The Logical Division of Ideas in Essay 1

\begin{tabular}{|l|c|c|c|}
\hline Logical division of ideas & Unity & Coherence & Cohesion \\
\hline Introductory Paragraph & - & - & - \\
\hline Body Paragraph 1 & $\sqrt{ }$ & $\sqrt{ }$ & $\sqrt{ }$ \\
\hline Body Paragraph 2 & $\sqrt{ }$ & $\sqrt{ }$ & - \\
\hline Body paragraph 3 & $\sqrt{ }$ & $\sqrt{ }$ & - \\
\hline
\end{tabular}

Essay 2 addresses a title "Tana Toraja Culture" and it has an introductory paragraph, body paragraphs, but it does not have a concluding paragraph. The detailed construction of the essay can be seen below:

\section{Essay 2: Analytical Exposition}

\section{Introductory Paragraph}

Tana Toraja Culture

Tana Toraja, literally mean land of Toraja, is a highland situated in the region of Southern Sulawesi. It is well known as the land of heavenly kings. A land with with green and rice terraces, tall limestone and bamboo grave with blu misty mountains.

\section{Body Paragraph 1}

The local Toraja food some Chinese or western food, and the Torajan specialty called pa pio which actually chicen/pork fish with vegetable in bamboo tube while washing it down with local Torajan palm. Coffee lovers may also find that region is famous for coffee and drinking it there is not only fress but really cheap.

\section{Body Paragraph 2}

The Torajan people still practice many ancient rites, many says that we are obsess with the idea of death. There are cave graves, hanging graves, baby tree graves and even mass laughter of buffaloes.

\section{Body Paragraph 3}

These are my culture bring you a sense of strangeness yet. (By participant B)

\section{The Essay 2 Logical Division of Ideas}

The logical division of ideas of each paragraph in Essay 2 presents unity, coherence and cohesion that can be found in correct sentences and a dual linkage between sentences and paragraphs. Moreover, it is also significant to pay attention to the correct vocabulary usage, necessary transition signal or commas, grammatical and lexical cohesions.

\section{Introductory Paragraph}

Tana Toraja, literally mean land of Toraja, is a highland situated in the region of Southern Sulawesi. It is well known as the land of heavenly kings. A land with with green and rice terraces, tall limestone and bamboo grave with blu misty mountains.

The unity of introductory paragraph in Essay 2 upholds its integral parts expressed in the topic sentence "Tana Toraja, literally means land of Toraja, is a highland situated in the region of Southern Sulawesi" and the supporting sentences match with the single topic "Tana Toraja culture" under discussion. Nevertheless, they are not followed by the inclusion of a concluding sentence to highlight the paragraph summery and restatement of key points.

Pertaining to coherence, the first two sentences stick together because of a logical thought and use of a single transition signal as, indicating that the idea in the first sentence can be connected with the idea in the second sentence. A different things happens to the third sentence. It is not regarded as a sentence since it has no verb and, by considering its pattern, it can be stated that it becomes a continuum of the previous sentence. In terms of cohesion, this paragraph lacks the correct grammar and "the relations of meaning" (Tanskanen, 2006). In addition, the misspelled word blu (rather than blue) and the absence of comma (,) to connect the sentence with the third one engenders the grammatical mistake. Even, an introductory paragraph without a concluding sentence like this is uncommon.

\section{Body Paragraph 1}

The local Toraja food some Chinese or western food, and the Torajan specialty called pa pio which actually chicen/pork fish with vegetable in bamboo tube while washing it down with local Torajan palm. Coffee lovers may also find that region is famous for coffee and drinking it there is not only fress but really cheap.

The supporting (body) paragraph 1 does not fulfill the criteria of unity because its topic sentence has nothing to do with discussing a single topic the local Toraja food (Local Torajan Food). This paragraph has no concluding sentence resulting in the lack of summary of key points or overall ideas expressed in the previous sentences. Limited supporting sentences can also be another major weakness to ponder.

In line with the coherence, each sentence does not stick together due the incorrect use of transition signals or connectors not only...but also, but other connectors such as or, and, which, while, and that are attached to poorly constructed sentences. In addition, its cohesion marked by the unrelated meanings of words including misspelled words chicen, fress (chicken, fresh) and the absence of comma (,) in the phrase pork fish with vegetable (pork, fish with vegetable) delineates a misleading grammatical context, 


\section{International Journal of Science and Research (IJSR) \\ ISSN (Online): 2319-7064 \\ Index Copernicus Value (2013): 6.14 | Impact Factor (2014): 5.611}

along with poor vocabulary usage, semantic and lexical cohesions to connect ideas in sentences effectively.

\section{Body Paragraph 2}

The Torajan people still practice many ancient rites, many says that we are obsess with the idea of death. There are cave graves, hanging graves, baby tree graves and even mass laughter of buffaloes.

The supporting (body) paragraph 2 does not meet the criteria of unity because it suffers from a weakness that the integral parts (the topic sentence and the supporting sentence) do not sustain each other to discuss a single topic the Torajan People and their rituals. Even, the absence more supporting sentences and a concluding sentence worsens the weak unity. In dealing with coherence, sentences stick together, and the use of transition signals that and and indicates that each sentence in the paragraph coheres fairly well.

However, its cohesion is unclear because of an incorrect sentence that cannot communicate the idea well, for example, "The Torajan people still practice many ancient rites, many says that we are obsess with the idea of death." It indicates that the word-level mistake called rites should possibly mean rituals. The indefinite pronoun "many" can be followed by a noun, for example people/experts, and in this case, it becomes a plural subject "many people" that requires a plural verb say (not says).

Then, the collocation obsess (about something) is wrongly written to be obsess (with something) without considering its passive form. The unnecessary use of word laugher means something else that does not match with the plural noun buffaloes. The correct form is slaughter (the killing of animals for their meat). Therefore, the sentences should be correctly reconstructed, "The Torajan people still practice many ancient rituals. Many people say that we are obsessed about the idea of death. There are cave graves, hanging graves, baby tree graves and even mass slaughter of buffaloes."

This short body paragraph is not a final product, meaning that it can be refined to make it more complete than the previous one in terms of paying attention to a three-part structure of an essay paragraph namely topic sentence, supporting sentences and a concluding sentence. Thus, the weak paragraph cannot present a close relation of meanings in the contexts of how the essay writer constructs correct sentences, along with vocabulary richness, semantic and lexical cohesions within them.

\section{Concluding Paragraph?}

These are my culture bring you a sense of strangeness yet.

The concluding paragraph does not meet the criteria of unity, coherence and cohesion because it has only one sentence even though it is incorrectly constructed. The pseudo-subject (there) is wrongly used. The correct form of the subject should be a singular demonstrative pronoun "this" that can be followed by the singular linking verb is because the noun is written in a plural form (culture) and the subordinate conjunction that functioned to connect the first clause and the second one is missing.
Then the plural verb bring should be changed into a singular verb brings that agrees with the singular noun culture. Meanwhile, the coordinate conjunction yet is improperly used, so it should be removed from the sentence. Thus, the correct form of the sentence should be rewritten like this, "This is my culture that brings you a sense of strangeness." It can be proved in the following table.

Table 5: The Logical Division of Ideas in Essay 2

\begin{tabular}{|l|c|c|c|}
\hline Logical division of ideas & Unity & Coherence & Cohesion \\
\hline Introductory Paragraph & $\sqrt{ }$ & $\sqrt{ }$ & - \\
\hline Body Paragraph 1 & - & - & - \\
\hline Body Paragraph 2 & - & $\sqrt{ }$ & - \\
\hline Body paragraph 3 & - & - & - \\
\hline
\end{tabular}

Regardless of the fact that Essay 3 has no title, it has three paragraphs consisting of an introductory paragraph, and two supporting (body) paragraphs, but it does not have a concluding paragraph. The detailed elaboration of the essay can be seen in the following:

\section{Essay 3: Analytical Exposition}

\section{Introductory Paragraph}

As human being in democratic countries, even a newborn has rights. Rights are allowance granted for those who are eligible to pursue something in their life. As long as it doesn't bother the rights of other people. Meaning to say, even if people have rights, they are not free to do anything they want.

\section{Body Paragraph 1}

There are many kinds of right, but lets focus on my favorite rights: active rights and passive rights. The fundamental is that people have to struggle to achieve active rights, whether in order to get passive rights, one does not need to do anything since it is granted by the government for example. On the other hand, passive rights in one country can be active one in the other country, for example is the right to vote for president. We see that Libya is one of the democratic countries in the world, but people have to fight/attack the government to let them choose a president.

\section{Body Paragraph 2}

Active rights can be passive one too. In developed country, one does not have to fight for the education, even the government pay them and allocate $52 \%$ of the budget in US for example. Another example is the right to pursue happiness. In US, this right is the most crucial right but this might make a great difference if applied in Indonesia for example, because happiness varies a lot from one people to another, and our country is considered as multicultural one. (By participant C)

\section{The Logical Division of Ideas}

The logical division of ideas of each paragraph in Essay 3 are examined thoroughly to comprehend sustainable integral parts namely unity, coherence and cohesion expressed in correct sentences and the linkage between sentences and paragraphs. In this case, the correct vocabulary usage, or necessary transition signal or commas, grammatical and lexical cohesions should be considered as well. 


\section{International Journal of Science and Research (IJSR) ISSN (Online): 2319-7064 \\ Index Copernicus Value (2013): 6.14 | Impact Factor (2014): 5.611}

\section{Introductory Paragraph}

As human being in democratic countries, even a newborn has rights. Rights are allowance granted for those who are eligible to pursue something in their life. As long as it doesn't bother the rights of other people. Meaning to say, even if people have rights, they are not free to do anything they want.

In terms of a unity, the introductory paragraph of Essay 3 supports its integral parts although the topic sentence " $A s$ human being in democratic countries, even a newborn has rights" is poorly constructed. The fact is that the connector as attached to the subordinate clause "human being in democratic countries ..."does not make sense because there is no verb to emphasize the action of the doer (the subject). The adverb even in the main clause is used properly, but the adjective newborn requires a noun namely babies (newborn babies). The correct form of the topic sentence is Human beings and even newborn babies in democratic countries have rights. The idea behind it matches with the supporting ideas in the supporting sentences concerning human beings and their rights. The concluding sentence summarizes key points and over ideas expressed in the previous sentences, so the discussion of a single topic is more focused and clearer.

In terms of coherence, each sentence sticks together using a transition signal as long as and a relative pronoun who, indicating that the idea in one sentence can be connected with the idea in other sentences. In line with cohesion, the introductory paragraph puts forward "the relations of meaning" (Tanskanen, 2006) resulting in the pursuit of vocabulary richness, though, incorrect grammatical cohesion newborn (missing the plural noun babies attached to it: newborn babies - paralleled with the plural subject human beings) can be improved. The incorrect collocation granted for (somebody or something) can be changed into granted to (somebody or something) categorized as a lexical cohesion. Regardless of the fact, the meaning (a semantic element) is clearly expressed in this paragraph.

\section{Body Paragraph 1}

There are many kinds of right, but lets focus on my favorite rights: active rights and passive rights. The fundamental is that people have to struggle to achieve active rights, whether in order to get passive rights, one does not need to do anything since it is granted by the government for example. On the other hand, passive rights in one country can be active one in the other country, for example is the right to vote for president. We see that Libya is one of the democratic countries in the world, but people have to fight/attack the government to let them choose a president.

The supporting (body) paragraph 1 meets the criteria of unity because its integral parts (the topic sentence, and supporting sentences) support a single topic kinds of rights. Instead, this paragraph lacks a concluding sentence, so it cannot summarize the key points and overall ideas in the previous sentences. The coherence of each sentence in it is signaled by the correct use of transition signals or connectors since, on the other hand and but. However, grammatical mistakes such as lets and many kinds of right have to be changed into a correct form let us and a plural form many kinds of rights. Then the adverbial clause whether in order to get passive rights can be correctly reformulated to be whether to get passive rights or not or whether or not to get passive rights without a comma (,) preceded it and the term in order to should be omitted because it emphasizes the term to. Therefore, the correct form of the supporting sentence is "The fundamental difference is that people have to struggle to achieve active rights whether to get passive rights or not. The addition of a connector therefore can help construct the ensuing sentence, "Therefore, one does not need to do anything since it is granted by the government for example."

The absence of a plural form one in the phrase active one and the unnecessary addition of definite article the, a singular noun country in the phrase the other country, and a linking verb is after the phrase for example make the supporting sentence "On the other hand, passive rights in one country can be active one in the other country, for example is the right to vote for president" incomplete (a runon sentence) because of the unnecessary comma (,) after the phrase other country. Therefore, its correct form should be like this, On the other hand, passive rights in one country can be active ones in other countries, for example, the right to vote for a president.

\section{Body Paragraph 2}

Active rights can be passive one too. In developed country, one does not have to fight for the education, even the government pay them and allocate $52 \%$ of the budget in US for example. Another example is the right to pursue happiness. In US, this right is the most crucial right but this might make a great difference if applied in Indonesia for example, because happiness varies a lot from one people to another, and our country is considered as multicultural one.

The supporting (body) paragraph 2 meets the criteria of unity because it has integral parts (the topic sentence and supporting sentences) that sustain each other to discuss a single idea active rights. Even though the absence a concluding sentence influences the sustainable unity of summarizing key points or overall and supporting ideas, the supporting sentences stick to the communication of a single idea active rights. In dealing with coherence, sentences stick together indicated by the effective use of transition signals because and and.

The cohesion is unclear because certain incorrect sentences (Active rights can be passive one too. ... one does not have to fight for the education, even the government pay them...) or words (one people, multicultural one) cannot convey the meaning clearly. The correct forms are Active rights can be passive ones too. ...one does not have to fight for the education, even the government pays him or her... a person and a multicultural one. It can be mapped out in the following table.

Table 6: The Logical Division of Ideas in Essay 3

\begin{tabular}{|c|c|c|c|}
\hline Logical division of ideas & Unity & Coherence & Cohesion \\
\hline Introductory Paragraph & $\sqrt{ }$ & $\sqrt{ }$ & - \\
\hline Body Paragraph 1 & $\sqrt{ }$ & $\sqrt{ }$ & - \\
\hline Body Paragraph 2 & $\sqrt{ }$ & $\sqrt{ }$ & - \\
\hline
\end{tabular}




\section{International Journal of Science and Research (IJSR) ISSN (Online): 2319-7064 \\ Index Copernicus Value (2013): 6.14 | Impact Factor (2014): 5.611}

University Students' Problems in Developing Logical Divisions of Ideas in the Expository Essays

The interview results indicated that participant A faced three problems in dealing with unity such as the difficulty in finding the topic of the essay, the inappropriate development of ideas in sentences and paragraphs and incorrect sentence constructions. Moreover, four cohesion problems she faced were in line with difficulties in determining correct dictions, neologism (new words), connections between sentences and paragraphs, and use of correct transitions. The cohesion was also problematic for her when dealing with linking ideas between sentences or paragraphs. Eventually, the emergent problem (meaning that it was unclassified in the planned code) she found was the disorganized logical division of ideas.

The interview with participant B showed a problem of unity concerned with how ideas in sentences could be united. Unfortunately, there was no relevant information obtained about coherence. A cohesion problem merely referred to the use of correct grammar. Furthermore, five emergent problems pertained to the difficulty in determining ideas to develop, illogical division of ideas, unclear explanation of ideas, topics development, and unorganized ideas.

The interview with participant $\mathrm{C}$ resulted in a problem relevant to the difficulty in integrating ideas within parts of sentences and paragraphs. However, no problem was identified in relation to coherence. A common problem on cohesion dealt with the limited vocabulary mastery worth considering. Most of all, seven emergent problems ranged from the difficulty in determining the generic structure of an essay, organization of ideas to the complexity on how to begin writing, how to explore ideas, how to find out ideas to be exposed and how to construct supporting ideas.

\section{Conclusion}

The essays in question present unity, coherence and cohesion because topic sentences in each paragraph match with the supporting ideas expressed in the supporting sentences. However, certain sentences cannot stick together because transition signals are used improperly. The relations of meanings in each sentence are unclear. They highlight the consistency of the single idea expressed in the topic sentence, and sentences are connected to each other properly by using transition signals and the relations of meanings within sentences are expressed well. In contrast, the absence of concluding sentences or paragraphs engenders the conveyance of summary and key points, and the paragraph suffers from a drawback of grammatical and lexical cohesions in the form of lack of vocabulary richness and incorrect grammar including "the relations of meaning"(Tanskanen, 2006).

Referring to the interview results, participants ${ }^{\text {ee }}$ problems in developing logical divisions of ideas involved the difficulty in finding the topic of the essay, integrating ideas to the inappropriate development of ideas in sentences and paragraphs and incorrect sentence constructions. In terms of cohesion, they found difficulties in determining correct dictions, neologism, connections between sentences and paragraphs, and use of correct transitions. The cohesion was also problematic in a way that linking ideas between sentences or paragraphs proved inaccurate resulting partly from the limited vocabulary mastery. The emergent problems prevailing in students ${ }^{\text {ee }}$ essays showed an illogical division of ideas and the difficulty in exploring ideas. Besides, topics development was part of the difficulty in determining the generic structure of an essay and organization of ideas.

\section{References}

[1] Arnaudet, Martin, L \& Barrett, Maria Ellen. 1984. Approaches to Academic Reading and Writing. New Jersey: Englewood Cliffs.

[2] Bloom, Lynn Z. 2007. The Essay Connection Reading for Writers. Boston: Houghton Mifflin Company.

[3] Creswell, John W. 2003. Research Design Qualitative, Quantitative and Mixed Methods Approaches. California: SAGE Publications.

[4] Dastjerdi, H.H. \& Samia, S.H. 2011, May. Quality of Iranian EFL Learners' Argumentative Essays: Cohesive Devices in Focus. Mediterranean Journal of Social Sciences. Retrieved February 4, 2014 from www.meser.org.

[5] Davis, L. \& McKay, S. 1996. Structures and Strategies An Introduction to Academic Writing. Queensland: MacMillan Publishers Australia PTY LTD.

[6] Harper, Graeme. 2010. Foreword on Experience. In Donnelly, Dianne (Ed.) New Writing Viewpoints Does the Writing Workshop Still Work? Bristol: Multilingual Matters St. Nicholas House.

[7] Hinkel, Eli. 2004. Teaching Academic ESL Writing: Practical Techniques in Vocabulary and Grammar. London: Lawrence Erlbaum.

[8] Hyland, Ken. 2003. Second Language Writing. Cambridge: Cambridge University Press.

[9] Karim, Mariana \& Rachmadie, Sabrony. 1996. Writing. Departemen Pendidikan dan Kebudayaan Direktorat Jenderal Pendidikan Tinggi Proyek Pendidikan Tenaga Akademik [Ministry of Education and Culture Directorate General of Higher Education A Project on Educational Workers]. Jakarta: Jalan Pintu Satu, Senayan.

[10]Lindsay, D. 2011. Scientific Writing = Thinking in Words. Victoria: CSIRO Publishing.

[11]Nation, I.S.P. 2009. Teaching ESL/EFL Reading and Writing ESL \& Applied Linguistics Professional Series. London: Routledge.

[12] Olson, C.B. 2003. The Reading/Writing Connection: Strategies for Teaching and Learning in the Secondary classroom (Companion Website). New York: Allyn \& Bacon/Longman.

[13] Oshima, A \& Hogue, A. 1997. Introduction to Academic Writing. New York: Pearson Education, Inc.

[14] Oshima, A \& Hogue, A. 1999. Introduction to Academic Writing. New York: Pearson Education, Inc.

[15] Oshima, A \& Hogue, A. 2007. Introduction to Academic Writing Level 3 ( $3^{\text {rd }}$ edition). New York: Pearson Education, Inc.

[16] Phillips, Deborah. 2004. Longman Introductory Course for the TOEFL Test. New York: Pearson Education, Inc. 
[17] Sherman et al. 2010. Paragraphs. Retrieved from http://www.selu.edu/acad_research/programs/writing_c enter February 5, 2014.

[18] Tanskanen, Sanna-kaisa. 2006. Collaborating towards Coherence: Lexical Cohesion in English Discourse. Amsterdam: John Benjamins Publishing Co.

[19] Wallwork, A. 2011. English for Writing Research Papers. New York: Springer Science + Business Media, LLC.

[20]Wulff et al. 2009. Facilitating Coherence across Qualitative Research Papers. The Weekly Qualitative Report Volume 2 Number 6 February 16, 2009 32-44 http://www.nova.edu/ssss/QR/WQR/coherence.pdf

\section{Author Profile}

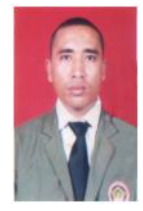

Anselmus Sudirman teaches courses in translating and interpreting, writing and English for accountancy at Universitas Sarjanawiyata Tamansiswa (UST) Yogyakarta, Indonesia where he obtained his undergraduate degree (S.Pd.) from the English Education Department in 2003. He earned his master degree (M.Hum.) in English Language Teaching from Universitas Sanata Dharma (USD) Yogyakarta, Indonesia in 2007. He also edits papers and journals of undergraduate and master students. His scholarly work includes Teaching Speaking: How to Develop University Students' Communicative Competence published by Jurnal Wacana Akademika Vol. 3, Number 8, July 2010, Pentingnya Strategi-strategi Menulis untuk Meningkatkan Kemampuan Menulis Mahasiswa [The Importance of Writing Strategies to Improve University Students ${ }^{\text {ee }}$ Writing Competence] published by Jurnal Wacana Akademika Vol. 3, Number 8, July 2011, Optimizing Students' Competence in Writing Weekly Journals (the unpublished research in 2013), Curiosity on Paragraph Writing (a book published in 2014), and The Impact of Revision Strategies on University Students' Writing Competence (a research conducted in 2015). His short stories and stories (Morsels of Life) were published by Mingguan Hidup magazine and Reader's Digest Indonesia magazine. His research interest is English language teaching particularly the teaching of writing for university students.

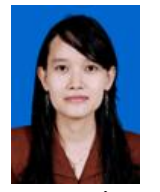

Luky Tiasari is a lecturer at the English Education Department of Universitas Sarjanawiyata Tamansiswa (UST) Yogyakarta, Indonesia where is currently teaching courses in Introduction to Linguistics, Sociolinguistics, Psycholinguistics, Syntax \& Semantics and Introduction to Teaching English for Specific Purposes. She obtained both her undergraduate degree (S.Pd.) and master degree (M.Pd.) in English Education Department from Universitas Negeri Semarang (UNNES), Indonesia. She is the author of ONE-On Nitty-gritty English (2014), TWO-The Willynilly Okay (2015), Hello Introduction to Linguistics (2015), Hello Psycholinguistics (2015), Hello Syntax and Semantics (2015). Her academic papers include Power Relationship between Examiners and the Examinee on Thesis Examination (2013), Creative Teaching of Speaking \& Writing through Narrative Text (2014), Fostering Students' Engagement in Teaching English Using SAYY (2015), and The Effective Use of Texts in Developing Students' Creativity (2015). Her scholarly research focuses primarily on English language teaching and linguistics. 